\title{
Comparison of Image Improvement Method on Parasite Images of Malaria
}

\author{
Rika Rosnelly*1, Linda Wahyuni ${ }^{2}$ \\ 1,2 Universitas Potensi Utama, Engineering and Computer Sciences Faculty \\ Email : ${ }^{1 *}$ rikarosnelly@gmail.com, ${ }^{2}$ linda@potensi-utama.ac.id \\ *Corresponding author
}

\begin{abstract}
Improved image is a process on the image that initially has a quality that is less good or has noise. In this image improvement operation image quality will be improved so that the image produces better quality. Image improvement methods used are contrasted stretching, histogram equalization, low pass filter and Gaussian filtering. In this study compare contrast stretching method, histogram equalization, low pass filter and Gaussian filtering to improve image quality. Performance of each method would be calculated by finding the value of Mean Square Error (MSE) and Peak Signal to Noise Ratio (PSNR). This study compares contrast stretching methods, histogram equalization, low pass filter and Gaussian filtering to improve image quality. Total data of malaria parasite image is 120. The data consist of image of malaria parasite falciparum, vivax, malaria along with stage that is ring, trophozoite, schizont and gametocyte. Evaluate the performance of each method by finding Mean Square Error (MSE) and Peak Signal to Noise Ratio (PSNR) values. The result is a contrast stretching provides better image quality against malaria parasite image.
\end{abstract}

Keyword - contrast stretching, histogram equalization, Gaussian filtering, MSE, PSNR

\section{INTRODUCTION}

The image of malaria parasite comes from Health Laboratory Center of North Sumatera Province. Image of malaria parasites still contain of image with less good quality. To overcome this we used image repair method to improve image contrast. Based on the problem, this research used image improvement method. There are four image repair methods used for comparisons such as contrast stretching, histogram equalization, low pass filter and Gaussian filtering. Research of [1][2][3][4][5] used the median filter as an image repair method for malaria parasites identification. Research of [6][7] used local histogram equalization. Research of [8][9] using median filter and filtering SUSAN and [10] used Susan's filtering approach. Research of [11] used dark stretching. Research of [12] used a median filter and Laplacian filter. Previous studies had not compared the four methods of image repair using contrast stretching, histogram equalization, low pass filter and Gaussian filtering to identify three types of malaria disease consisting of malaria, falciparum and vivax with ring stage, trophozoite, skizon and gametocyte. The result of image improvement method cannot be distinguished because it looks the same between contrast stretching method, histogram equalization, low pass filter and Gaussian filtering. It measured the performance of MSE (Mean Square Error) and PSNR (Peak Signal to Noise Ratio) image. Performance evaluation technique used MSE and PSNR scores. The value of 
MSE and PSNR was one technique that can distinguish values for image quality improvement [13]. The best image repair method will be used in the next stage of the region of interest (ROI) and finally used to identify the type of malaria and its stadium.

\section{RESEARCH METHOD}

Some of the problems encountered in image processing are the problem of contrast and brightness. In order to overcome this problem, we use image improvement method to improve image contrast. Research [11] performs image and segmentation improvement used dark stretching technique for Plasmodium falciparum in thick blood. The results showed dark stretching technique can improve image quality and can distinguish between object and background.

Research [14] carried out enhanced RGB color image (Red Green Blue) in the $\mathrm{YCbCr}$ color space using K-Means. Image enhanced by RGB color conversion process to $\mathrm{YCbCr}$ color space. Furthermore each $\mathrm{YCbCr}$ section was checked with Luminance $(\mathrm{Y})$, Chrominance $\mathrm{Cb}$ and $(\mathrm{Cr})$ histograms and each channel is enhanced by histogram matching. After all the channels are upgraded they are combined into one image and show the best results and then ready for the next process.

The comparison model of image improvement method in malaria parasite image can be seen in Figure 1.

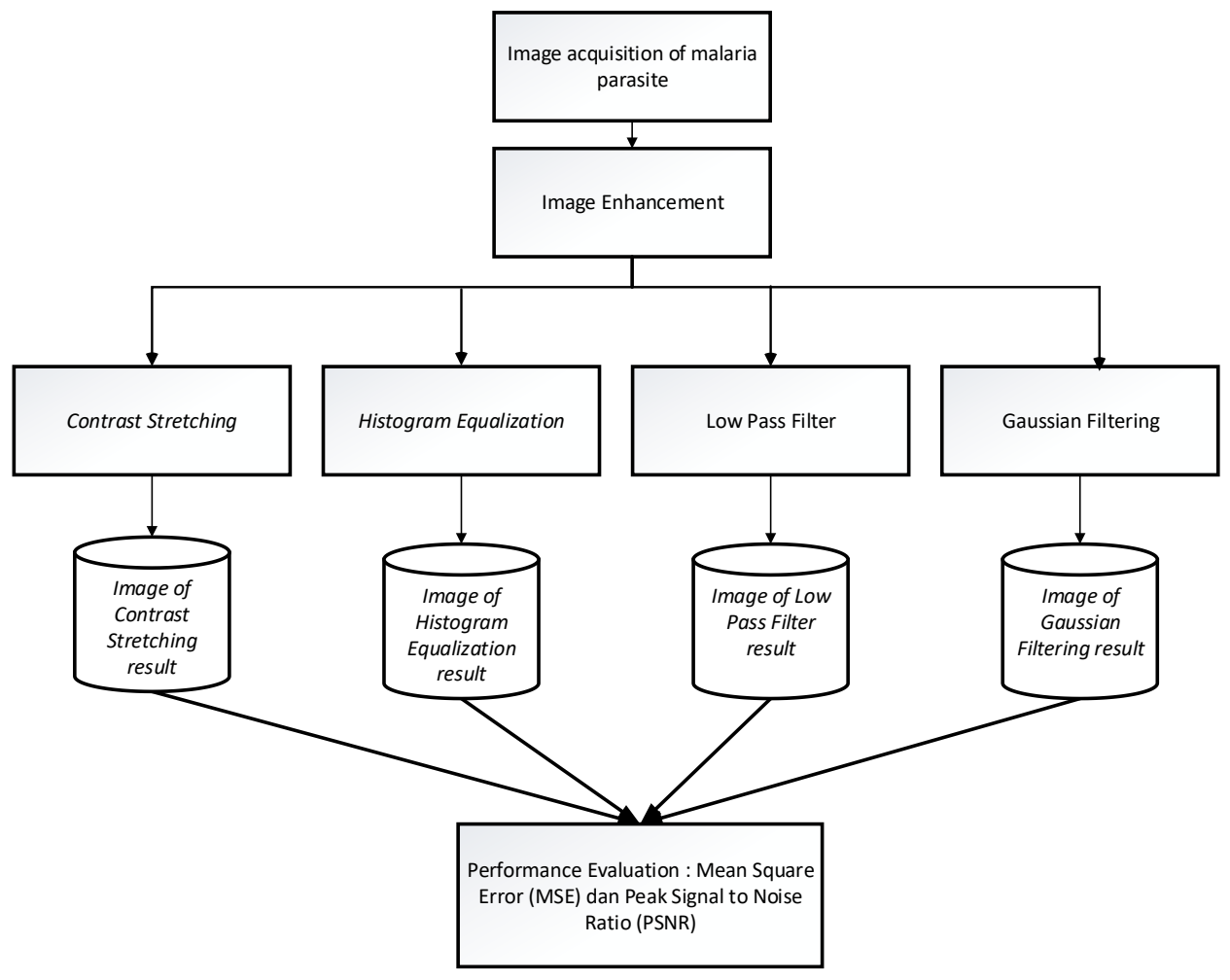

Figure 1. Comparison of Image Improvement Method

Figure 1 showed comparison of image improvement method starting from acquisition of malaria parasite image, then done image improvement process. Performance evaluation 
techniques used MSE and PSNR [15]. Image improvement methods use four methods: contrast stretching, histogram equalization, low pass filter and Gaussian filtering.

\subsection{Image Acquisition}

At the acquisition stage, malaria parasite image sample was conducted at Health Laboratory Center of North Sumatra Province parasitological section. The samples of the malaria samples were re-examined and then labeled and verified by the Health Laboratory Office of the Province of North Sumatra. There were three types of malaria parasites present in the Health Laboratory Office of North Sumatera Province consist of falciparum, vivax and malaria with four stages namely ring, trophozoite, schizont and gametocyte.

At the Central Laboratory of Health of the Province of North Sumatra, there were preparations that had been given Giemsa stained. Before the examination, prepare oil emersion drip then did the image taking. The process of malaria parasite image intake used digital microscope with 1000 times magnification. The image data of the malaria parasite type was then stored for future use.

In the re-examination process was accompanied by laboratory personnel to know the type of malaria parasite along with. Imagery could be seen on the monitor screen. The type of malaria parasite and its stadium could be seen in Figure 2 [16].

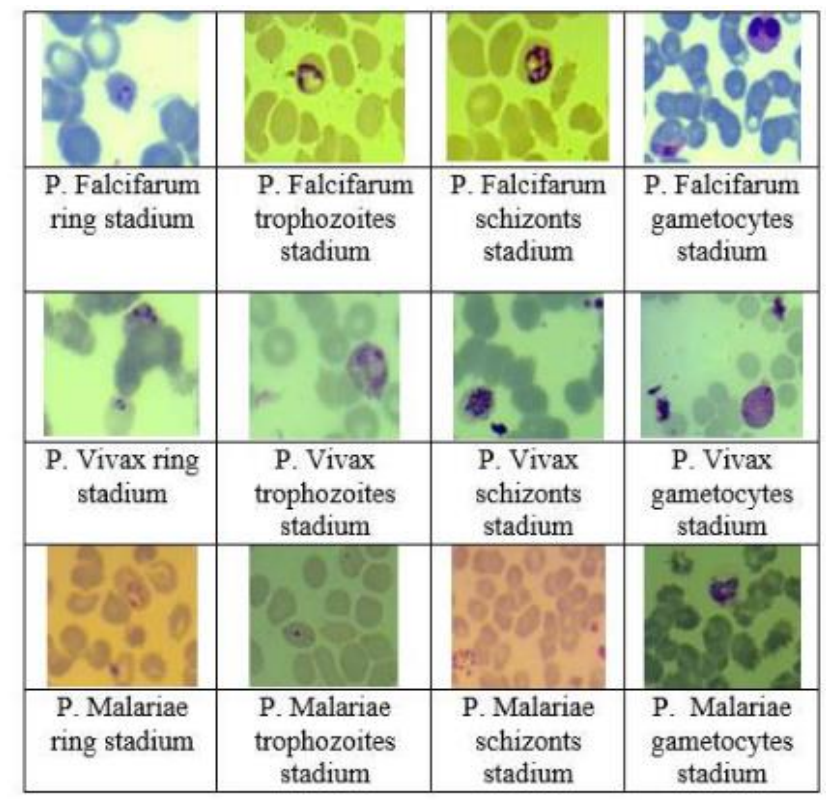

Figure 2. Image of Falciparum Malaria Parasite, Vivax, Malaria with Four Stages Resource: Center for Health Laboratory of North Sumatra Province

\subsection{Image enhancement}

Image of malaria parasite was still there image that have image quality less good. The problem can be improved image quality. At this stage the image repair method used four methods of image enhancement as a comparison to get better image quality results. The method used was contrast stretching, Histogram equalization, Low pass filter, Gaussian filtering. 
In the next stage is done for the image storage process of contrast stretching, histogram equalization, low pass filter and Gaussian filtering.

\subsubsection{Contrast Stretching}

Contrast is a bright and dark distribution in a picture. One method of image repair is the contrast stretching. Contrast stretching is a technique used to obtain a new image with better contrast than the contrast of its original image [17].

The contrast stretching process included an image processing process that was point processing, which meant this process depends on the intensity value (gray level) of a pixel, independent of the other pixels around it [18]. The explanation of the contrasting stretch can be seen in Figure 3 [19].

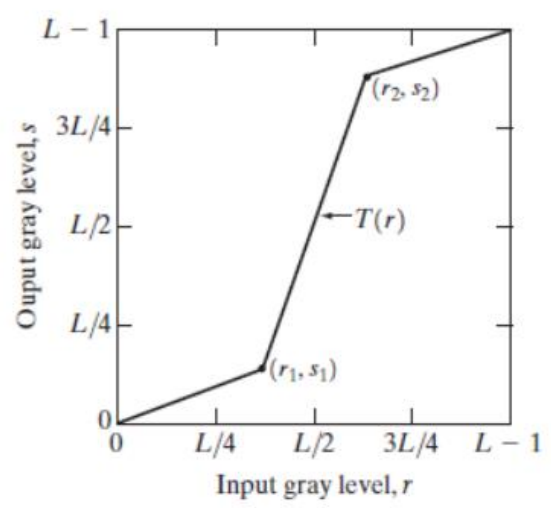

Figure 3. Contrast Stretching Function

Figure 3 views to change the pixel contrast value of the original pixel using the provisions:

a. there will be a change in pixel contrast value if the value of the gray level $r 1<=r 2$ and $s 1<=$ s2

b. there will be no change in the pixel contrast value if the value of the gray level $r 1=r 2$ and s1 $=$ s2

c. will transform the image into a binary image (thresholding) when $r 1=r 2$ and s1 $=0$ and $s 2$ $=255$

\subsubsection{Histogram Equalization}

Histogram equalization is a process that can change the distribution of gray degree values in the image so that it becomes uniform. The alignment of the histogram is obtained by altering the gray degree of a pixel $(r)$ with a new gray degree $(s)$ with a T transformation function [17]. The equation for histogram equalization can be seen in equation 1 .

$p_{r}\left(r_{k}\right)=\frac{n_{k}}{M N} \quad k=0,1,2, \ldots, L-1$

$n_{k} \quad=$ the pixel value on the gray degree rk $M N$ = the total number of pixels in the image

\subsubsection{Low Pass Filter}


Low pass filter is a filter process where the image taking with a smooth intensity gradient and high intensity difference will be reduced, and then the resulting is the relative increase of high frequency image components without increasing the noise. The resulting image is sharper than the original image. This can be used to highlight the unclear part of the image [17]. The function of the low pass filter can be seen in equation 2 .

$\sum_{j} \sum_{i} H(i, j)=1$

Kernel's regulation for low pass filteris:

1. All Kernel's coefficient must positive

2. The number of all Kernel's coefficient must equal 1.

\subsubsection{Gaussian filtering}

Gaussian filtering is one type of spatial filtering, based on the Gaussian opportunity distribution function. Gauss function in two dimensions can be seen in equation 3.

$f(x, y)=e^{-\frac{x^{2}+y^{2}}{2 \sigma^{2}}}$

$f(x, y)$ is image intensity function, $\sigma$ is deviation standard, $x$ and $y$ are image point coordinate.

\subsection{Performance Evaluation by using Mean Square Error (MSE) andPeak Signal to Noise Ratio (PSNR)}

The result of evaluation of four methods of image repair is used, that is calculate the value of PNSR (Peak Signal to Noise Ratio) and MSE (Mean Square Error). At first it begins with four methods of image repair used. Next perform the calculation of the value of PNSR and MSE on each image improvement result with the original image that has been converted to grayscale.

\subsubsection{MSE (Mean Square Error)}

Mean Square Error is used to compare the initial image with the result of image improvement method. The smaller value of MSE the more similar the two images. The Mean Square Error formula can be defined in equation 4 [20]:

$$
M S E=\frac{1}{k l} \sum_{i=0}^{k-1} \sum_{j=0}^{l-1}[P(i, j)-Q(i, j)]^{2}
$$

The value of $k$ is for the length and I for the width, $P(i, j)$ is the original image and $Q(i, j)$ is the image of the image improvement.

\subsubsection{PSNR (Peak Signal to Noise Ratio)}

In the image improvement required comparison between the original image with image repairs image. Size used is Peak Signal to Noise Ratio. The higher value of PSNR the better the image quality improvement results. The PSNR formula is seen in equation 5. 


$$
P S N R=10 \log _{10}\left(\frac{255^{2}}{M S E}\right)
$$

\section{RESULT AND DISCUSSION}

Based on the results of the designed model, the following result of methods and discussion for each step.

\subsection{Improved Image Results}

After the process of image retrieval of malaria parasite, the next process of image repair to get better image quality so that image can be processed easily by computer. Image improvement methods use contrast stretching, histogram equalization, low pass filter and Gaussian filtering.

\subsubsection{Image Improvement Results using Contrast Stretching}

Image improvement methods in this study use contrast stretching, histogram equalization, low pass filter and Gaussian filtering. Figure 4 shows examples of grayscale image results and image repair results using the contrast stretching method.

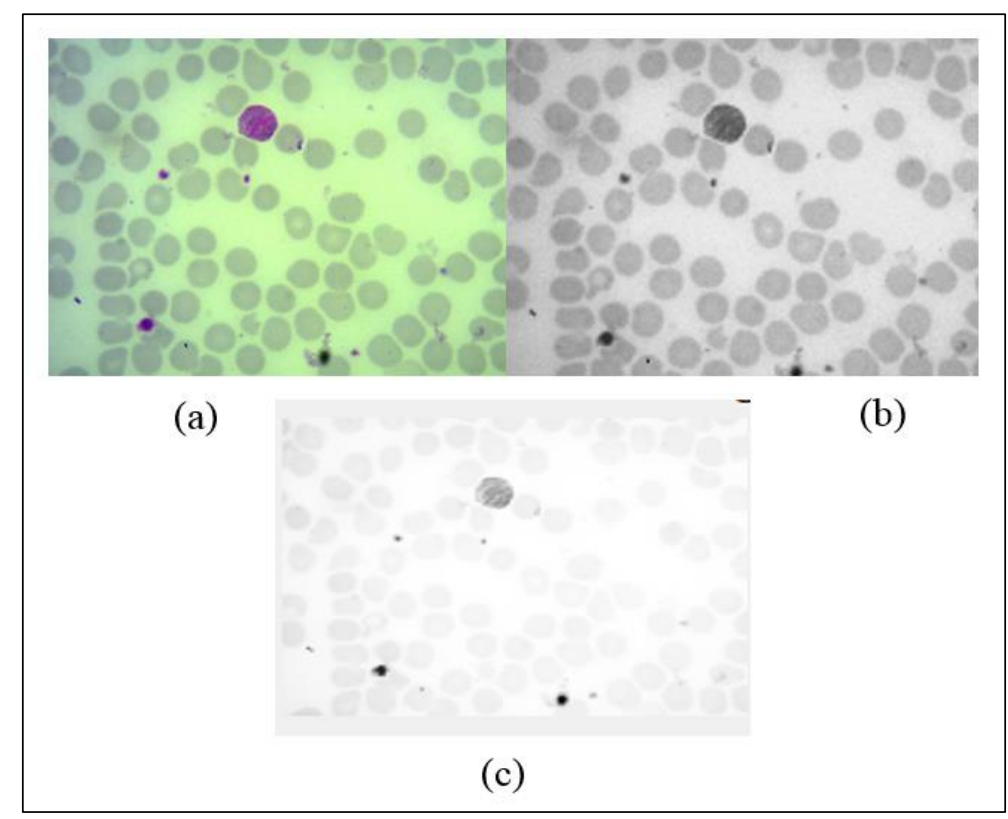

Figure 4.Image Improved Result (a) Initial Image (b) Grayscale result Image From Figure 4 (a), (c) Contrast Stretching Image From Figure 4 (b)

Figure 4 (a) Preliminary image or original image. Figure 4 (b) image of grayscale result. Figure 4 (c) result of image improvement process using contrast stretching. Can be seen image results using contrast stretching more contrast than the initial image. 


\subsubsection{Image Improvement Results using Histogram Equalization}

Image improvement method used next is histogram equalization method. Figure 5 showed an example of image improvement using histogram equalization method.

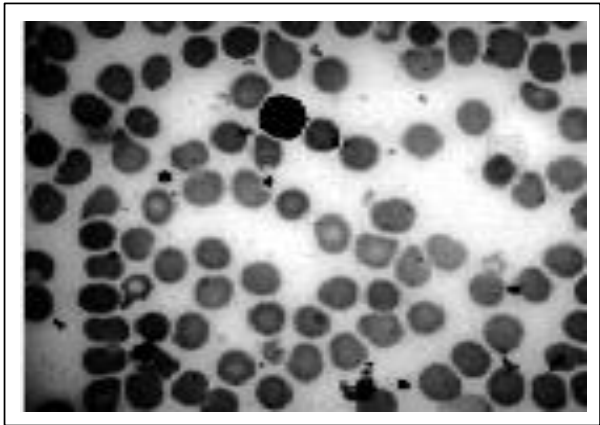

Figure 5. Results Improved Image with Histogram Equalization

How to image retrieval image histogram equalization image starts with the original image load then do the grayscale process. Furthermore, histogram equalization process is done. The results in Figure 5 can be seen gray degree result of image improvement using histogram equalization more evenly where histogram equalization is change the gray degree distribution at image become uniform.

\subsubsection{Image Improvement Results using Low Pass filter}

The next image repair method used is the low pass filter method. Figure 6 showed an example of image repair using a low pass filter method.

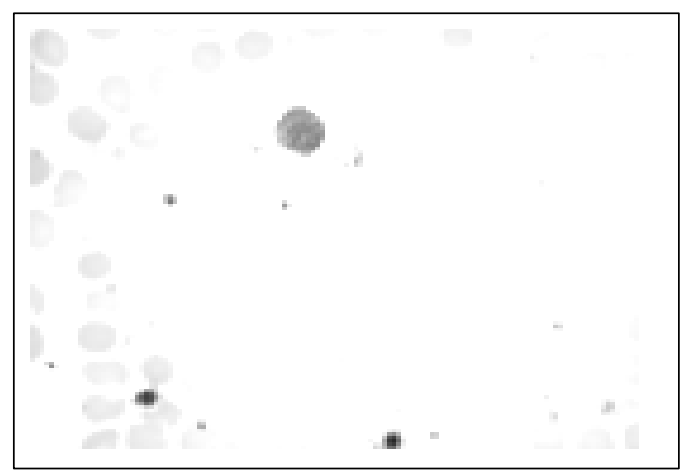

Figure 6. Improved Image Improvement with Low Pass filter

How to image retrieval of the low pass image filter image begins with the original image load subsequently performed low pass filter process. Figure 6 image repair results using smoother and more blurred low pass filter.

\subsubsection{Image Improvement Results using Gaussian filtering}

The image repair method used next is the Gaussian filtering method. Figure 7 showed the example of the image improvement using the Gaussian filtering method. 


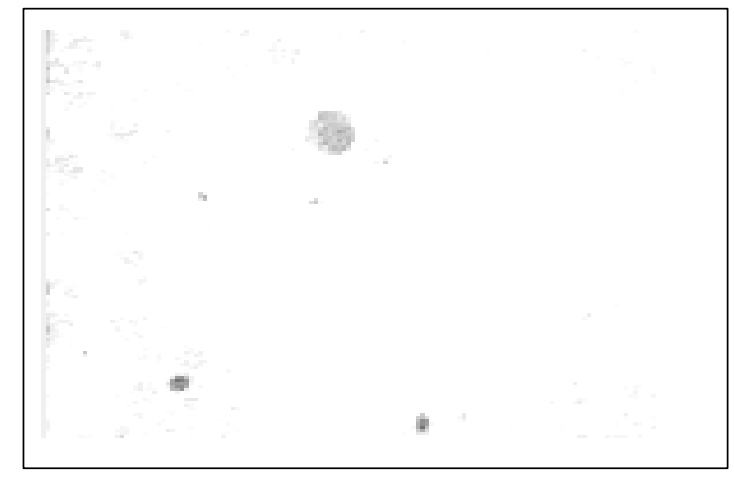

Figure 7. Improved Image Result with Gaussian filtering

How to image retrieval result of image Gaussian filtering begins with original image load, and then did Gaussian filtering process. The result of Figure 7 showed the image improvement using the Gaussian filtering image seen slightly blur.

\subsection{Evaluation Result}

Performance evaluation techniques on image types of malaria parasites and stadiums use Mean Square Error (MSE) and Peak Signal to Noise Ratio (PSNR) to find out which method is better to use in image repair. This is one of the contributions to this research. Image improvement method can be measured by visual technique that is by comparing original image with result image. The problem experienced is the image of the malaria parasite is difficult to see the difference without having a good knowledge base. PSNR is a useful calculation to determine the value of a generated image. MSE serves to determine the error of the image of the improvement [21]. The value of PSNR is determined based on the size or magnitude of the MSE value in the image. The greater the value of PSNR the better the results on the image display results. Conversely, the smaller the value of PSNR the more unfavorable the results obtained on the image results. The unit of value of PSNR is decibel (dB). The relationship between the value of PSNR and MSE is the greater the value of PSNR, the MSE value is smaller. MSE value is greater than the display on the image will be less good results. Conversely, the MSE value is smaller than the image of the results will be better evaluation results using MSE and PSNR can be seen in Table 1.

Table 1. Average score of PSNR and MSE images

\begin{tabular}{|c|c|c|c|c|c|c|c|}
\hline \multicolumn{2}{|c|}{$\begin{array}{l}\text { Contrast } \\
\text { Stretching }\end{array}$} & \multicolumn{2}{|c|}{$\begin{array}{l}\text { Histogram } \\
\text { Equalization }\end{array}$} & \multicolumn{2}{|c|}{$\begin{array}{l}\text { Low Pass } \\
\text { Filter }\end{array}$} & \multicolumn{2}{|c|}{$\begin{array}{l}\text { Gaussian } \\
\text { Filtering }\end{array}$} \\
\hline PSNR & MSE & PSNR & MSE & PSNR & MSE & PSNR & MSE \\
\hline 33,3833 & 43,9667 & 2,6203 & 4272,4050 & 13,4348 & 3424,1501 & 29,4237 & 3676,8424 \\
\hline
\end{tabular}


Table 1 shows that good PSNR and MSE values are using contrast stretching method when compared with other methods, that is equal to $33,3833 \mathrm{~dB}$ and 43,9667 .

\section{CONCLUSION}

Based on the description in the previous chapters, that by using PSNR and MSE to evaluate the result of image improvement, the better PSNR and MSE values are using contrast stretching with the value of $33,3833 \mathrm{~dB}$ and 43,9667 when compared with the three methods used namely histogram equalization, low pass filter and Gaussian filtering.

\section{FUTURE WORKS}

Development for further research is to conduct Region of Interest (ROI) automatically.

\section{REFERENCES}

[1] Anggraini, D., Nugroho, A.S., Pratama, C., Rozi, I.E., Iskandar, A.A. \& Hartono, R.N., 2011a, Automated status identification of microscopic images obtained from malaria thin blood smears. In Proceedings of International Conference on Electrical Engineering and Informatics (ICEEI), Bandung, Indonesia, pp. 1-6.

[2] Anggraini, D., Nugroho, A.S., Pratama, C., Rozi, I.E., Pragesjvara, V. \& Gunawan, M., 2011b, Automated status identification of microscopic images obtained from malaria thin blood smears using Bayes decision : a study case in Plasmodium falciparum. In Proceedings of International Conference on Advanced Computer Science and Information System (ICACSIS), Jakarta, Indonesia, pp. 347-352.

[3] Das, D., Ghosh, M., Chakraborty, C., Maiti, A.K. \& Pal, M., 2011, Probabilistic prediction of malaria using morphological and textural information. In Proceedings of International Conference on Image Information Processing (ICIIP), Shimla, India, pp. 1-6.

[4] May, Z., Aziz, M., Azreen, S.S. \& Salamat, R.a., 2013, Automated quantification and classification of malaria parasites in thin blood smears. In Proceedings of International Conference on Signal and Image Processing Applications (ICSIPA). Melaka, Malaysia, pp. 369-373.

[5] Somasekar, J., Reddy, A.R.M. \& Reddy, L.S., 2013, An efficient algorithm for automatic malaria detection in microscopic blood images. Global Trends in Information Systems and Software Applications (eds. by P.V. Krishna, M.R. Babu \& E. Ariwa), pp. 431-440. Springer, Berlin, Heidelberg.

[6] Arco, J., G'orriz, J., Ram'irez, J., 'Alvarez, I. \& Puntonet, C., 2015, Digital image analysis for automatic enumeration of malaria parasites using morphological operations. Expert Syst. Appl. 42, 3041-3047.

[7] Suradkar, P.T., 2013, Detection of malarial parasite in blood using image processing. Int. J. Eng. Innovative Technol. 2, 124-126.

[8] Khan, M.I., Acharya, B., Singh, B.K. \&Soni, J., 2011, Content based image retrieval approaches for detection of malarial parasite in blood images. Int. J. Biometrics Bioinf. 5, 97-110. 
[9] Soni, J., 2011, Advanced image analysis based system for automatic detection of malarial parasite in blood images using susan approach. Int. J. Eng. Sc. Technol. 3, 5260-5274.

[10] Ahirwar, N., Pattnaik, S. \& Acharya, B., 2012, Advanced image analysis based system for automatic detection and classification malarial parasite in blood images. Int. J. Inf. Technol. Knowl. Manag. 5, 59-64.

[11] Hanif, N.S.M.M., Mashor, M.Y. \& Mohamed, Z., 2011, Image enhancement and segmentation using dark stretching technique for Plasmodium falciparum for thick blood smear. In Proceedings of 7th International Colloquium on Signal Processing and its Applications (CSPA). Penang, Malaysia, pp. 257-260.

[12] Savkare, S. \& Narote, S., 2011, Automatic detection of malaria parasites for estimating parasitemia. Int. J. Comput. Sci. Secur. 5, 310-315.

[13] Pratiarso, A., Yuliana, M., Hadi, M.Z.S., Bari, F., Brahim., 2012, Analisa PSNR Pada Teknik Steganografi Menggunakan Spread Spectrum, The $14^{\text {th }}$ Industrian Electronics Seminar, Surabaya.

[14] Abbas, N. dan Mohamad, Z., 2013, Microscopic RGB Color Images Enhancement for Blood Cells Segmentation in $\mathrm{YCbCr}$ Color Space for K-Means Clustering, Journal of Theoretical and Applied Information Technology, page 117-125.

[15] Fajrin, H.R., 2016, Perbandingan metode untuk perbaikan kualitas citra mammogram, Jurnal Simetris, Vol 7 No 2 November 2016, ISSN: 2252-4983.

[16] Balai Laboratorium Kesehatan Propinsi Sumatera Utara, 2011, Buku Pedoman Kesehatan Sumatera Utara.

[17] Gonzalez, R.C. dan Woods, R.E., 2002, Digital Image Processing, Edisi ke-2, Prentice-Hall, Inc., Upper Saddle River, New Jersey 07458.

[18] Wakhidah, N., 2011, Perbaikan Kualitas Citra Menggunakan Metode Contrast Stretching, Jurnal Transformatika, Volume 8, No. 2, 78-83.

[19] Gonzalez, R.C. dan Woods, R.E., 2008, Digital Image Processing, Edisi ke-3, Prentice-Hall, Inc., USA.

[20] Poobathy, D., \& Chezian, R. M., 2014, Edge detection operators: Peak signal to noise ratio based comparison. International Journal of Image, Graphics and Signal Processing, 6(10), 55-61. doi:10.5815/ijigsp.2014.10.07.

[21] Acharya, 2005, Image Processing: Principles and Applications, Wiley-Interscience, ISBN 0-471-71998-6. 